\title{
MORFOMETRIA DAS UNIDADES DE DRENAGEM DO MÉDIO CURSO DO RIO ANIL, ILHA DO MARANHÃO
}

\author{
Thaine OliveiraRodrigues ${ }^{(\mathrm{a})}$; Gilberlene Serra Lisboa ${ }^{(\mathrm{b}) ;}$ Quesia Duarte daSilva ${ }^{(\mathrm{c})}$ \\ (a). Departamento de Geografia/Faculdade de Geografia Bacharelado/UEMA/thaine_ro@yahoo.com.br \\ (b). Departamento de Geografia/Mestranda em Geografia/UEMA/gilberlene_serra@yahoo.com.br \\ (c). Professora Doutora no Departamento de Geografia da UEMA/quesiaduartesilva@ hotmail.com
}

\section{EIXO: BACIAS HIDROGRÁFICAS E RECURSOS HÍDRICOS: ANÁLISE, PLANEJAMENTO E GESTÃO}

\begin{abstract}
Resumo
O presente artigo objetiva aplicar a morfometria nas unidades de drenagem do médio curso da bacia hidrográfica do Anil, que possui uma área de $16,03 \mathrm{~km}^{2}$, o médio curso foi subdividido em 8 (oito) unidades que melhor possibilitam a aplicação dos cálculos morfométricos. Utilizando parâmetros como densidade de drenagem, índice de circularidade, Fator de forma, coeficiente de manutenção e índice de sinuosidade, e a partir do resultado das equações e posterior análise estatística obter quais unidades de drenagem possuem sujeição às inundações e enxurradas na área de estudo, e compreender como a análise favorece na compreensão das unidades para melhor gestão do ambiente.
\end{abstract}

Palavras chave: Morfometria. Unidades de drenagem. Médio curso do Anil

\section{Introdução}

Os processos erosivos e as inundações, por exemplo, são fenômenos naturais que podem ser significativamente alterados, e geralmente intensificados de forma negativa, pela ação antrópica, o que os torna veículos causadores de grandes prejuízos humanos e econômicos à sociedade (IPT, 2006, p.77).

Desta forma, é correto dizer, que ambos os fenômenos supracitados, tem suas causas naturais e sociais. Conforme Machado e Torres (2012), parte das causas naturais pode ser melhor entendida com o estudo mais detalhado das caracteristicas próprias das bacias hidrográficas, e, para tal, um dos recursos comumente utilizados tem sido a análise morfométrica, que consiste na caracterização de parâmetros morfológicos que explicitam alguns indicadores físicos da bacia. Ainda para os autores, a morfometria abrange um grande número de parâmetros que melhor permitem caracterizar um ambiente de uma bacia, sua predisposição à ocorrência de alguns eventos e sua incompatibilidade com algumas atividades humanas.

Lindner, Gomig e Kobiyama (2007), acentuam que para a elaboração de projetos de prenvenção e defesa contra eventos hidrológicos como estiagens e inundações, que ocorrem na bacia hidrográfica, os índices morfométricos são importantes pressupostos. 
Contudo, a análise morfométrica vai além de apenas dados numéricos, ela permite compreender a probabilidade de ocorrências das inundações, e de posse dessas informações as áreas podem ser classificadas quanto à intensidade desses eventos e posteriormente um planejamento urbano pode ser aplicado em tais regiões, pois seguidamente a população que reside em áreas urbanas são afetadas por eventos de inundações.

Diante disto, entende-se a importância da aplicação da morfometria para compreensão da área de estudo. O médio curso da bacia hidrográfica do Anil, possui uma área de $16,03 \mathrm{~km}^{2}$ e está totalmente inserida no município de São Luís, Ilha do Maranhão, e a área em questão tem apresentado índices de inundações e enxurradas.

\section{Metodologia}

O médio curso da bacia hidrográfica do Anil está localizado a noroeste do município de São Luís, Ilha do Maranhão, para o alcance dos objetivos acerca da análise morfométrica o médio curso foi dividido em oito unidades de drenagem. A divisão em unidades de drenagem permite uma melhor caracterização da área estudada e permite que a análise morfométrica seja aplicada em todos os tributários.

A análise morfométrica das unidades de drenagem foram feitas a partir das características geométricas, de relevo, e das características da rede de drenagem. Na caracterização geométrica foram determinados a área $(\mathrm{A})$, perímetro $(\mathrm{P})$, fator de forma $(\mathrm{Kf})$ e o índice de circularidade (Ic).

O fator de forma $(\mathrm{Kf})$ relaciona a forma da bacia com um retângulo, correlacionando arazão entre a largura média e o comprimento axial da bacia da montante à jusante. Villela e Mattos (1975) citam que uma bacia com fator de forma baixo é menos suscetível a enchentes. Para determinar o fator de forma foi utilizada a Equação [1]:

$\mathrm{Kf}=\frac{A}{L^{2}}$

$\mathrm{A}=$ área da bacia em $\mathrm{km}^{2}$

$\mathrm{L}=$ comprimento da bacia em $\mathrm{km}$.

Conforme Silva (2012), o índice de circularidade (Ic) é adimensional e foi proposto inicialmente por Müller (1953) e Schumm (1956). Quanto mais próximo o resultado deste índice for da unidade (1), mais circular será a bacia de drenagem e, consequentemente, a bacia será mais suscetível às inundações. Este parâmetro foi calculado a partir da equação [2] a seguir:

Ic $=\underline{12,57 \times \mathrm{A}}$, onde:

$\mathrm{P}^{2}$

$\mathrm{P}=$ perímetro. 
Para a caracterização quanto ao relevo das unidades de drenagem foi feito o cálculo para o índice de sinuosidade. Para a classificação dos canais quanto à sinuosidade, utilizou-se a proposta de Dury (1966), citado por Christofoletti (1980), ou seja, os canais com Is igual ou superior a 1,5 (adimensional) são considerados meandrantes, enquanto que os canais com Is menor que 1,5 são classificados como retos. O índice de sinuosidade (Is) foi calculado, conforme Antoneli e Thomaz (2007) a partir da equação [3]:

$I s=\underline{L v}$

Lr

$\mathrm{Lv}=$ comprimento verdadeiro do canal principal $(\mathrm{km})$;

$\mathrm{Lr}=$ comprimento em linha reta do canal principal.

Para as características referentes a rede de drenagem, a densidade de drenagem (Dd) é a relação entre o comprimento total de canais e a área da bacia e para seu cálculo, devem-se considerar todos os rios tanto os perenes como os temporários (Horton, 1945apud Silva, 2012). Para caracterização da rede de drenagem, foram determinados o comprimento do canal principal, o comprimento total dos canais, a densidade de drenagem e a ordem da bacia. Segundo Christofoletti (1969), valores elevados de Dd indicam áreas com pouca infiltração e melhor estruturação dos canais. A densidade de drenagem (Dd) foi obtida por meio da Equação [4]. Dd $=\mathrm{Lt} / \mathrm{A}$, onde $\mathrm{Lt}=$ comprimento total dos canais; e $\mathrm{A}=$ área da bacia .

O cálculo para o Coeficiente de manutenção (Cm), foi proposto por Schumm (1956), esse índice tem a finalidade de fornecer a área mínima necessária para a manutenção de um metro de canal de escoamento. Tem por objetivo revelar a área mínima necessária $\mathrm{em} \mathrm{m}^{2}$ para a manutenção de um metro de canal de escoamento (SILVA et. Al. 2003; CHRISTOFOLETTI, 1980).

Granell-Pérez (2001), explica que o coeficiente de manutenção é o inverso da densidade de drenagem, indicando assim a área necessária $\mathrm{em}^{\mathrm{km}}$ para manter ativo um $\mathrm{km}$ de canal fluvial. É um dos índices mais importantes para a caracterização do sistema de drenagem e é calculado pela seguinte expressão [5]: $\mathrm{Cm}=1 / \mathrm{Dd}$ onde, $\mathrm{Cm}=$ coeficiente de manutenção; $\mathrm{Dd}=$ densidade de drenagem

\section{Resultados e Discussão}

A figura 1 mostra a divisão do médio curso em unidades de drenagem para a aplicação da morfometria, as áreas tracejadas são áreas definidas como inter-bacias, que são localidades com drenagem pouco definida, portanto a morfometria não pôde ser aplicada nessas áreas, pois os resultados não seriam compatíveis com o proposto neste trabalho. Após a delimitação e aplicação dos cálculos e análises estatísticas a figura 2 foi gerada para demonstrar os valores e sua susceptibilidade aos eventos supracitados. 


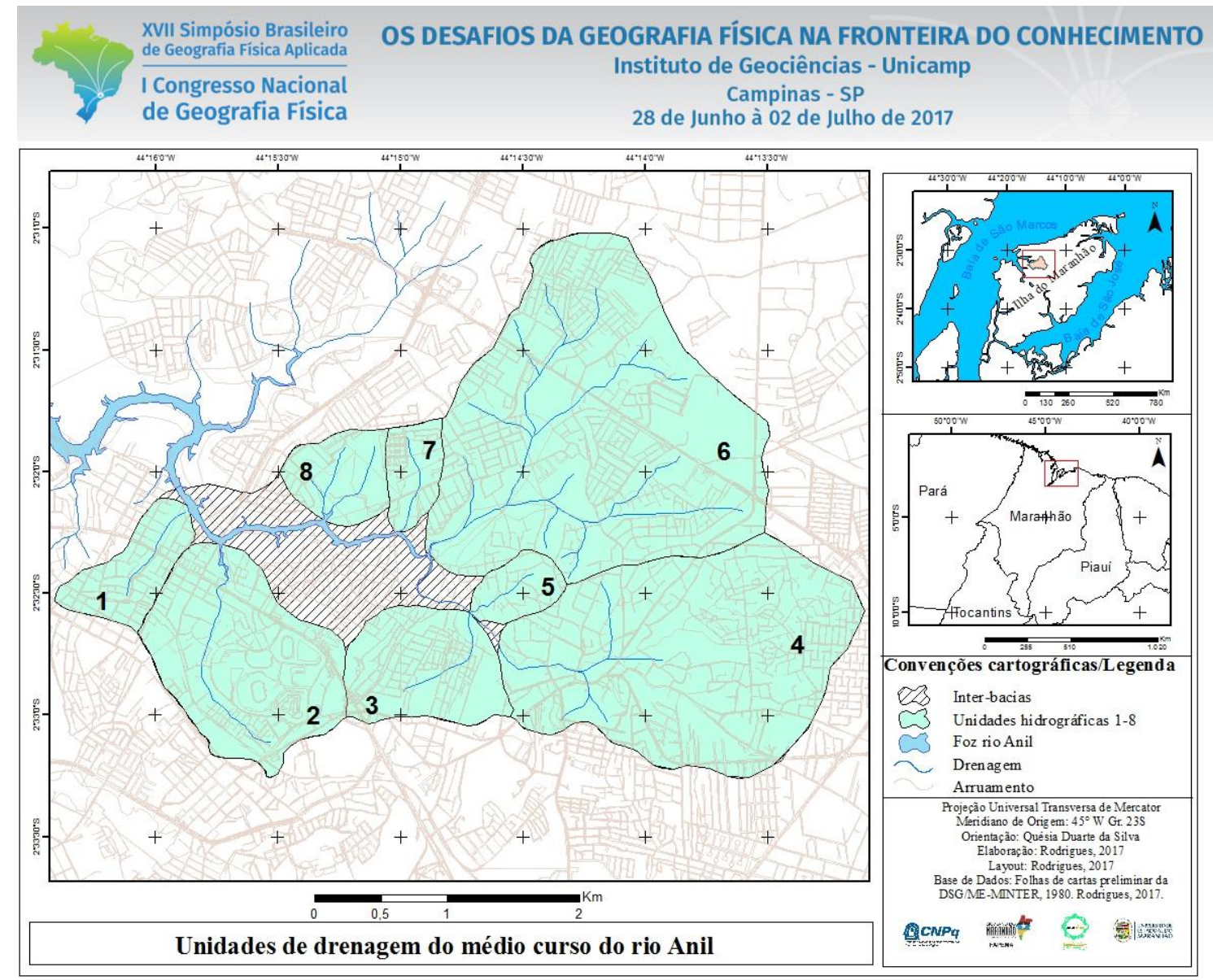

Figura 1: Mapa de unidades de drenagem do médio Anil

Os resultados quanto ao Fator de forma as unidades são em sua maioria entre circular e intermediária, concordando com o índice de Circularidade que também apresentou em sua maioria unidades com formas mais circulares, onde as unidades $4,3,2,5$ e 8 são circulares e as demais apresentam formas entre alongada e intermediárias. Essas unidades que apresentam bacias com formas circulares, proporcionam um escoamento mais lento, quanto mais próximo de 1,0 a bacia apresentar sua morfometria, mais circular será sua forma, portanto as unidades com formatos circulares tendem a serem sujeitas à inundações súbitas no canal principal quando as precipitações são mais intensas e afetam toda extensão da bacia, pois o porte de água no flúvio, proveniente das vertentes e dos tributários, tende à simultaneidade, concentrando-se num espaço de tempo curto.

Quanto ao índice de sinuosidade todos os canais obtiveram resultados de restos, com baixa sinuosidade, conforme a drenagem original da área de estudo, retiradas das cartas DSG de 1:10.000 de 1980, e com imagens recentes de satélite percebe-se um aumento significativo de tributários com mudanças morfológicas significativas e com altas taxas de poluição das águas.

A maioria das unidades de drenagem em relação a Dd apresentam entre muito baixa a média sujeição a vários fatores, dentre eles, a ocorrência de inundações, apenas as unidades 5 e 7 apresentam entre alta e muito alta sujeição aos eventos citados. É importante lembrar que as 
demais unidades apresentam boa capacidade de infiltração da água pluvial no solo e que originalmente tendem a possuir maior cobertura vegetal próximo aos tributários.

O índice de Coeficiente de Manutenção funciona de forma inversa a Densidade de Drenagem, enquanto que Dd baixa é indicadora de boa capacidade de infiltração da agua no solo e de cobertura vegetal, o Cm baixo significa que o canal não consegue manter ativo um $\mathrm{Km}$ de canal fluvial. Quanto mais alto for a classe do $\mathrm{Cm}$ melhor capacidade o canal terá de se manter ativo, e no médio curso a maioria dos canais possuem de muito baixa a baixa capacidade de se manter ativo, apenas as unidades 4 e 6 possuem melhor coeficiente de manutenção do canal.

\section{Considerações Finais}

Diante disto, entende-se que em sua maioria, e considerando todos os parâmetros morfométricos as unidades de drenagem possuem sujeição às inundações súbitas no canal principal e em seus tributários. E esses eventos têm se intensificado decorrente do uso e ocupação indevidos do solo, gerando maior índice de impermeabilização e de retirada da mata ciliar para construção de residências e/ou acúmulo de materiais tecnogênicos nas margens de tributários.

Entende-se, portanto, que o grande problema das bacias de drenagem urbanas é a modificação morfológica dos canais e de sua paisagem original, numa análise superficial, a vegetação é certamente um dos aspectos fundamentais, pois a alteração na vegetação original é facilmente percebida, e a eliminação da mesma gera solo exposto, que na maioria das vezes não é possível uma reconstituição, e a partir desse solo exposto a densidade de drenagem vai ficar alta, provocando aumento nas probabilidades de ocorrência de inundações.

\section{Bibliografia}

CHRISTOFOLETTI, A. Geomorfologia. São Paulo: Edgard Blucher, 1980.

DURY, H. G. TidalStreamActionand Valley Meanders. GeographicalResearch, 1969.

GRANELL-PÉREZ, M. D. C. Trabalhando geografia com as cartas topográficas. Ijuí/RS: Editora Unijuí, 2001.

LINDNER, E. A.; GOMIG, K.; KOBIYAMA, M. Sensoriamento remoto aplicado à caracterização morfométrica e classificação do uso do solo na bacia do rio Peixe/SC.Anais do XIII Simpósio Brasileiro de Sensoriamento Remoto. Florianópolis, 21-26 abr. 2007.

MULLER, G. Methods in SedimentaryPetrology. New York: Stuttgart, 1953.

MACHADO, P. J. de O.; TORRES, F. T. P. Introdução à hidrogeografia. São Paulo: Cengage Learning, 2012.

SCHUMM, S. A. Meanderwavelengthof aluvial rivers. Science, v. 157, 1956.

SILVA, Q. D. Mapeamento geomorfológico da Ilha do Maranhão/ Tese de Doutorado. Presidente Prudente- Universidade Estadual de São Paulo, 2012. 
VILLELA, S. M.; MATTOS. A Hidrologia aplicada. São Paulo: McGraw-Hill do Brasil, 1975. 